\title{
NEW REFINEMENTS OF THE ERDÖS-MORDELL INEQUALITY
}

\author{
JIAN LIU
}

Abstract. In this paper, we present further extensions of two known refinements of the ErdösMordell inequality. Several other new refinements of the Erdös-Mordell inequality are established as well. Some closely related interesting conjectures which have been checked by computer are also proposed.

Mathematics subject classification (2010): 51M16.

Keywords and phrases: Erdös-Mordell inequality, triangle, interior point.

\section{REFERENCES}

[1] A. Avez, A short proof of a theorem of Erdös and Mordell, Amer. Math. Monthly. 100, (1993), 60-62.

[2] F. F. ABI-KhUZAM, A trigonometric inequality and its geometric applications, Math. Inequal. Appl., 3, (2003), 437-442.

[3] C. Alsina, R. B. Nelsen, A visual proof of the Erdös-Mordell inequality, Forum Geom., 7, (2007), 99-102.

[4] N. Dergiades, Signed distances and the Erdös-Mordell inequality, Forum Geom.,4, (2004), 67-68.

[5] P. ERdös, Problem 3740, Amer. Math. Monthly. 42, (1935), 396.

[6] S. Gueron, I. Shafrir A weighted Erdös-Mordell inequality for polygons, Amer. Math. Monthly. 112, (2005), 257-263.

[7] W. JANOUS, Further inequalities of Erdös-Mordell type, Forum Geom., 4, (2004), 203-206.

[8] V. Komornik, A short proof of the Erdös-Mordell theorem, Amer. Math. Monthly. 104, (1997), 5760 .

[9] J. LiU, A new proof of the Erdös-Mordell inequality, Int. Electron. J. Geom., 4(2), (2011), 114-119.

[10] J. LIU, On a geometric inequality of Oppenheim, J. Sci. Arts. 18(1), (2012), 5-12.

[11] J. LiU, Sharpened versions of the Erdös-Mordell inequality, J. Inequal. Appl., 2015, 206(2015).

[12] J. LiU, Refinements of the Erdös-Mordell inequality, Barrow's inequality, and Oppenheim's inequality, J. Inequal. Appl., 2016, 9(2016).

[13] L. J. Mordell, D. F. Barrow, Solution of Problem 3740, Amer. Math. Monthly. 44, (1937), 252 254.

[14] D. S. Mitrinović, J. E. PeČARIĆ, On the Erdös Mordell's inequality for a polygon, J. College Arts Sci, Chiba Univ., B-19, (1986), 3-6.

[15] D. S. Mitrinović, J. E. PeČarić, V. Volenec, Recent Advances in Geometric Inequalities, Kluwer Academic Publishers, Dordrecht-Boston-London, 1989.

[16] B. MalešEvić, M. Petrović, B. Popkonstantinović, On the Extension of the Erdös-Mordell type inequalities, Math. Inequal. Appl., 17, 269-281(2014)

[17] N. OzeKi On Paul Erdös-Mordell inequality for the triangle, J. College Arts Sci, Chiba Univ., 2, (1957), 247-250.

[18] A. OppenheIm, The Erdös-Mordell inequality and other inequalities for a triangle, Amer. Math. Monthly. 68, (1961), 226-230.

[19] R. A. Satnoianu, Erdös-Mordell type inequality in a triangle, Amer. Math. Monthly. 110, (2003), 727-729.

[20] A. SAKURAI, Vector analysis proof of Erdös’ inequality for triangles, Amer. Math. Monthly. 8, (2012), 682-684. 
[21] L. SI, B. W. HE, G. S. LENG, Erdös-Mordell inequality on a sphere in $R^{3}$, J. Shanghai Univ. Nat. Sci. 10, (2004), 56-58.

[22] L. F. TóтH, Lagerungen in der Ebene auf der Kugel und im Raum, Berlin, 1953.

[23] S. H. Wu, L. Debnath, Generalization of the Wolstenholme cyclic inequality and its application, Comput. Math. Appl., 53(1), (2007), 104-114. 